\title{
Article
}

\section{The US golf academy system and the twenty first century talent tourists! Future lines of research to understand this new golfing talent pathway}

Grecic, D., Carson, H.J., Collins, D., and Ryan, B.

Available at http://clok.uclan.ac.uk/17190/

Grecic, D. ORCID: 0000-0003-1487-8327, Carson, H.J. ORCID: 0000-00023785-606X, Collins, D., ORCID: 0000-0002-7601-0454 and Ryan, B. (2017) The US golf academy system and the twenty first century talent tourists! Future lines of research to understand this new golfing talent pathway. International Journal of Golf Science, 6 (1). pp. 1-19. ISSN 2168-7595

It is advisable to refer to the publisher's version if you intend to cite from the work. http://dx.doi.org/10.1123/ijgs.2016-0007

For more information about UCLan's research in this area go to http://www.uclan.ac.uk/researchgroups/ and search for <name of research Group>.

For information about Research generally at UCLan please go to http://www.uclan.ac.uk/research/

All outputs in CLoK are protected by Intellectual Property Rights law, including Copyright law. Copyright, IPR and Moral Rights for the works on this site are retained by the individual authors and/or other copyright owners. Terms and conditions for use of this material are defined in the policies page. 
This is a pre-proof corrected manuscript, as accepted for publication, of an article published by Human Kinetics in International Journal of Golf Science in June 2017, available online at: http://journals.humankinetics.com/doi/abs/10.1123/ijgs.2016-0007

PLEASE REFER TO THE FINAL PUBLISHED VERSION FOR CITING PURPOSES

The US Golf Academy System and the Twenty First Century Talent Tourists! Future Lines of Research to Understand this New Golfing Talent Pathway

David Grecic $^{1,2 *}$, Howie J. Carson ${ }^{1}$, Dave Collins ${ }^{1}$, and Brendan Ryan ${ }^{3}$

\footnotetext{
${ }^{1}$ Institute of Coaching and Performance, University of Central Lancashire, UK

${ }^{2}$ International Institute of Golf Education, University of Central Lancashire, UK ${ }^{3}$ BMR Sports Management, USA
}

* Correspondence concerning this paper should be addressed to David Grecic, Greenbank Building, Institute of Coaching and Performance, University of Central Lancashire, Preston, PR1 2HE, United Kingdom. E-mail: DGrecic1 @uclan.ac.uk 


\begin{abstract}
This paper addresses the rapid growth, popularity, and structure of US Golf Academies. Specifically, we highlight a phenomenon from a non-US golfing community's perspective; namely, that of the "talent tourist" (i.e., youth golfer) seeking to develop their playing skills and academic ability within a foreign talent pathway. With so much of these golfers' futures at stake (e.g., large financial costs and time dedicated), there is a surprising lack of research attention paid to these academies' talent development environments; for instance, their structure, position in the overall talent pathway, the quality of the approaches used, or reasons why golfers strive to enroll onto them. By addressing these issues, this paper will present the case for greater research interest and the development of more effective talent development pathways.
\end{abstract}

Keywords: coaching, elite performance, expertise, talent development 
The US Golf Academy System and the Twenty First Century Talent Tourists! Future Lines of Research to Understand this New Golf Talent Pathway

Many journalists and popular writers have recently commented on the development of sporting talent and, in doing so, widened the debate on how this process is best accomplished (Alfremow, 2015; Coyne, 2009; Epstein, 2014; Gladwell, 2009; McClusky, 2015; Syed, 2011). In somewhat of a contrast, evidence-based models highlight that the development of sporting expertise is not simply a linear physiological model (Balyi, 2002 but cf. Bailey et al., 2009) but rather a complex interaction of biological, psychological, and sociological factors (i.e., biopsychosocial; see Bailey, Collins, Ford, MacNamara, Toms, \& Pearce, 2009; Collins, Bailey, Ford, MacNamara, Toms, \& Pearce, 2012). Each of these factors separately, and in combination, present various and varying degrees of challenge that the performer must negotiate. Focused predominantly on the psycho-social elements of this challenge, what has been described as a "rocky road" (Collins \& MacNamara, 2012) relies on the deployment of specific, psycho-behavioural skill-sets, particularly during periods of transition (e.g., growth spurts, from club- to university-level participation) and challenge (e.g., higher-level competition, implementing technique changes).

These various complexities indicate the importance of a performer's interaction with coaches and support practitioners (Collins, Burke, Martindale, \& Cruickshank, 2015) and the opportunities to acquire, and master such skills; that is, the coaching environment (see Henrikson, Stambulova, \& Roessler, 2010, 2011; Martindale, Collins, \& Abraham, 2007; Martindale \& Mortimer, 2011). With this in mind, many have suggested how coaches can best develop performers in practice (Abraham, Collins, \& Martindale, 2006; Abraham \& Collins, 2011a; Cushion, Armour, \& Jones, 2003; Gilbert \& Trudel, 2013a, 2013b; Lyle, 2002; Schempp, McCullick, \& Mason, 2006), and establish the most conducive talent environment for athletes to develop (Henrickson et al., 2010; Martindale et al., 2007). 
In recent years, however, the talent pathway adopted by many international elite sporting organizations has appeared to neglect some of these well researched principles. Concurrently, although we claim no link here to causation as a consequence of neglecting biopsychosocial interactions, many golfers are opting to enroll onto an increasingly popularized alternative development system; the Golf Academy. Accordingly, there is a need to further understand this new destination as a starting point for future advances in international talent development, especially considering the potential disparities in sociocultural milieu between the home countries of the golfers and the American environment to which they are drawn (cf. Baliey et al., 2009).

Therefore, reflecting these various concerns, this paper addresses US golf academies as an exemplar template and their role in developing young, aspiring professional golfers from around the world; thus, creating what we refer to as the twenty first century talent tourists. In doing so, the paper proceeds through the following stages: (1) we provide an insight into the structure of the US talent pathway and the role that academies play within it; (2) next, we examine the development and operation of the US golf academies; and finally (3) we utilize literature to explore how the talent tourists (or rather their parents/sponsors!) are being encouraged to take up this alternative talent development option, therefore providing a critical discussion on how such academies are evaluated and assessed. While our discussion applies to many non-US countries (e.g., China, Korea, and Russia), and a range of sports (tennis and soccer in particular), we mainly focus on the situation and decisions facing England Golf's young golfers as a reflection of our most recent and involved work.

\section{US Golf's Talent Pathway: The Journey and Academies' Role}

The traditional route to professional sport participation in the US is through a talent pathway intertwined with the adolescent athlete's schooling and educational standing. For example, high school performances are exposed by the national media and monitored by US 
college athletic directors who have the budgets and ambition to offer future sporting scholarships (Green \& Houlihan, 2008), as depicted in "Route A" in Figure 1".

Subsequently, when at college or university, individuals are treated as full-time studentathletes and have every element of their training and academic study supervised and supported. In this talent development environment (TDE), players are exposed to nearprofessional levels of competition and performance expectations, through the National Collegiate Athletic Association (NCAA) Conference Championships and a plethora of live televised fixtures: Such events generate millions of dollars for their college which is reinvested into their sporting program offer. Indeed, within this culture, some studentathletes develop public profiles similar to many professional athletes (which, in effect, they are); their personal details becoming public as their sporting futures are seen as integral to the success and efficacy of their colleges' athletic programs (Smolianov, 2015). As a studentathlete, however, players are exposed to additional demands since they are concurrently enrolled upon a full-time degree, having first had to achieve a minimum Grade Point Average (GPA) based on their high school grades and an American College Testing (ACT) or Standard Attainment Test (SAT) score sufficient to grant them access to this sporting arena (NCAA, 2015a). Consequently, in order to protect the college's assets while imposing these demands on each student-athlete, co-operation between academic and coaching staff is essential, as well as individual player dedication and professionalism to achieve a combination of academic and sporting goals.

Following this exposure to pressurized competitive environments, college golfers seeking a career in professional tournament golf must qualify through a series of Tour School

\footnotetext{
${ }^{1}$ For UK readers when we refer to "college" in a US context we refer to a higher education institution which only offers academic study up to and including a four year baccalaureate honours degree. In the US system the term "university" is reserved for those higher education institutions that are permitted to deliver post graduate programs beyond the 4 year degree.
} 
events, with successful candidates attaining player membership of the US or European PGA Tours. From a pathway perspective, it is intended that the NCAA Conference Championship experience will develop the necessary skills and positively transfer to the professional level, but only if the players have been systematically prepared against a holistic talent model which develops those characteristics which will best support such a transfer (e.g., some of the important psychobehavioural skills evidently useful in education and sport; see Collins \& MacNamara, 2012; Martindale et al., 2007; Martindale \& Mortimer, 2011; MacNamara, 2011; Wyllemann, Alfermann, \& Lavellee, 2004). Many famous golfers have progressed through this pathway, including notable graduates such as Tiger Woods, Phil Mickelson, Jordan Spieth, Zach Johnson, and Bubba Watson. Furthermore, they have all been promoted on an international scale as products of its success (PGA Tour, 2015). In short, the pathway enjoys considerable status and endorsement, both within and outwith the sport.

While this pathway demonstrates a linear and embedded option along existing educational transitions, however, it does present a barrier to those seeking entry from outside the US educational system (e.g., language difficulties or sociocultural differences), and an almost insurmountable task for those who lack the requisite post-compulsory education academic standards. As such, entry level standards onto the USPGA Tour may be stifled by a limited pool of high-level golfers (NCAA, 2015a).

Recently, however, such a pathway has been augmented to provide golfers with an alternative entry point to compete for college scholarships, shown as Route B in Figure 1. The High School (16-18 years of age) competition program, though still robust and valuable in exposing young golfers to pressure environments, has been surpassed by the attention paid by college scouts to the national junior tours and players' performances at these individual events (AJGA, 2015; Gray, 2015). For the talent tourist, therefore, a new gateway into the golfing "promised land" has been opened. This shift away from high school golf over the 
past decade reflects the US college coaches' greater interest in more longitudinal scoring average, rounds under par, and head-to-head records as better indicators of whom to offer one of their prized scholarship awards (cf. a single performance observation of limited team numbers at the National High School Championship finals; Junior Golf Scoreboard, 2015a). Prioritization in this new way considers the level of competition across local and regional events to national events such as USGA sponsored tournaments (e.g., US Junior Boys and US Amateur). All players' results are collated and have resulted in a national ranking system provided by the National Junior Golf Scoreboard (NJGSC; Junior Golf Scoreboard, 2015b; Golfweek, 2015a), which ranks 8,618 boys and 2,819 girls who play in these US tournaments. It is such tournaments that golf academies use to prepare golfers to compete at and secure the requisite playing ranking to gain the talent scouts' attention (AJGA, 2015). Understandably therefore, for the talent tourists' parents/sponsors, access to this "shop window" might have become paramount in their thinking. For high school graduates too, participation, and success, at these junior tournaments can also serve to supplement an already established academic portfolio and increase their chances of securing a college scholarship (College Golf Combines, 2015).

With this change in focus for junior golfers and the NJGS arbitrary selection process now in place, progression into the next level of the talent pathway is reliant upon quality preparation and high-performance levels at these ranking events. With a US college scholarship worth in the value of $\$ 50,000$ per year for four years (NCAA, 2015b; Scholarship Statistics, 2015), plus additional benefits at some colleges which may total in excess of $\$ 100,000$ (Berkowitz, 2015; NCAA, 2015c), the rationale of the talent tourist and their parents for investing in a US golf academy program seems logical. Indeed, over the last few years a growing number of academy graduates have progressed through this talent pathway into a career in professional tournament golf. Some of the most high profile academy 
international alumni include Ryo Ishikawa, Bernd Wiesberger, Peter Uihlein, and Emilliano Grillo in the men's game, and Paula Creamer, Catriona Matthews, Jessica Korda, and Julieta Granada in the women's game to name but a few (IMG, 2015a). Such a well-promoted track record of alumni achieving their dreams through prestigious college scholarships, Professional Tour Cards, and tournament victories, surely serves to build/reinforce the desire of the talent tourists to access the pathway to golfing success.

\section{Contrasts with the England Golf Pathway}

As a contrast to Routes A and B described above, we present Route C in Figure 1 to depict the conventional pathway of elite-level amateur golfers in England, as described by England Golf in their Whole Sport Plan and strategic documents (England Golf, 2010; English Golf Union, 2011; England Golf Partnership, 2013; England Golf, 2014). Whereas both US pathways see golfers progress through an educational system immediately prior to entering the professional ranks, namely college education, the pathway in Route $\mathrm{C}$ is not similarly intertwined. As such, there is a seemingly less obvious need to progress along this dual route, with many young golfers perceiving a most practical option as giving up their education in order to dedicate more time to improving their golf performance. As an example of this attitude, consider the recently publicized opinion of lady golfer Charlie Hull who chose to exit formal education in order to further her professional golfing career (BBC, 2014). Entry into the US college educational system and, therefore, the opportunity to enter the NCAA Championships would be an impossibility for those golfers who decided to end their formal education at the compulsory age of 17 in the UK (i.e., termination at GCSE level, not continuing into A Level, etc.). Indeed, a similar fate will also befall other young European golfers who may leave their respective school system before completing their sports diplomas, or any Chinese players who decide to leave their sports schools at age 16. 
It is important to acknowledge that, in more recent iterations of England Golf's development plans, these important later stages of high school have been recognized through the establishment of an Advanced Apprenticeship in Sporting Excellence (AASE) program (selected students can take a golf performance-focused apprenticeship alongside their tertiary level studies at ages 16-18). Such a funded provision is, however, offered only to second tier golfers within the pathway, with more elite-level golfers selected onto national age group squads and teams with the explicit aim of progress to the full England Elite Squad (see Figure 1, Route C). For these latter golfers, the reality of participating in US college golf remains unchanged if not enrolled at A level/high school; for those in the second tier, in contrast, it may not be a matter of academic standard that prevents them from entering the college system, but rather their golf performances. Within the national squads, players access group and individual coaching (including specialist sport science support), play a negotiated competition schedule of amateur events in England and overseas, and compete for England in international team events and tournaments (e.g., Home Internationals). Although in past years this non-academic route has nurtured many golfers who have progressed into professional tournament golf, for example, Justin Rose, Chris Wood, Danny Willett, Matthew Baldwin, Eddie Pepperell, Tommy Fleetwood, and Tyrell Hatton, the opportunity of a fully funded US college program for English players has also been very attractive. Indeed English players such as Luke Donald, Paul Casey, and, at the time of writing this paper, 6 players in current England national teams, have taken this US option, therefore affording increased tournament participation and exposure to a greater competitor pool (Golfweek, 2015b). Ultimately, such an experience may inherently generate a better "rocky road," with opportunity for harder challenges and, therefore higher rewards.

\section{US Golf Academies: Their Development and Operation}


Sport performance academies can be dated back to 1978 when Nick Bolletteri opened the Nick Bolletteri Tennis Academy which, in 1987 was bought by International Management Group (IMG). In 1993, IMG expanded their product offerings and created a partnership with David Leadbetter in forming the first golf academy (IMG, 2015b). One year later this academy further expanded to include baseball and soccer; today, the offer includes US football, basketball, lacrosse, and athletics (IMG, 2015c). Indeed, across the US no less than 15 full-time golf academies exist (Saddlebrook, IMG, Core, Mike Bender, Eagles Dream, Gary Gilchrest, IJGT, JPGA, Greg Norman, ClubMed, Bishops Gate, Jim MacLean, Annika Golf, Tim Sheredy Golf Institute, and Missing Links Golf Academy), each offering an experience which includes schooling, accommodation and board, and a golf training program at a cost of between $\$ 30,000-\$ 80,000$ per year. Upon first investigation, all academies can be seen to offer a very similar product to the market with little differentiation evident for the consumer seeking to choose between them. Without independent comparison sites, offering objective league tables based on common performance metrics (such as percentage of players securing scholarships, value added score improvement data for players, etc.) decisions may simply be based parsimoniously on which academy's information was sourced first, which academy has been recommended to the talent tourist by their peers, or which was advised through one of a number of management placement companies which have come into the market to advise players of their options. A typical daily schedule at an academy would mirror that of a student-athlete in a college environment; players attend school from about $8 \mathrm{am}-1 \mathrm{pm}$, travel to the golf course to practice and play until 5pm, have dinner, and then complete either fitness sessions or study tables for the rest of the night. Integral to the program is an intense competition schedule, with students competing up to 20 weeks per year in local, regional, national, and international events in order to place themselves in the "shop window" for college scouts to notice. 
Typically, the practice schedule for part of each day would include instruction, play on the golf course, elements of fitness, mental training, and tournament support. Within this afternoon, students are provided with an individualized development program and allocated an instructor/mentor who enables the provision of consistent feedback and access to training in diverse areas such as course management or tournament preparation. Evenings see student-athletes undertake individual performance reviews of both their golf and academic progress with tutors to prevent the possibility of derailment from the talent pathway (Bishops Gate, 2015a; Core, 2015a; Gary Gilchrist, 2015; Greg Norman, 2015; IJGA, 2015; IMG 2015c; Jim MacLean, 2015; JPGA, 2015; Saddle Brook, 2015a ). We repeat here our observation from the previous section; that is, with such a homogenous offer in the market, on what basis are the talent tourists to make their decision?

Notably, each academy recruits a mixture of players from many different nationalities, excelling on many international stages. As a recent example, Chinese golfer Carl Yaun, 17, from Eagles Dream Golf Academy was invited to, and made the cut on, the European Tour at the Shenzhen International golf tournament (Eagles Dream, 2015). Such televised coverage and popular fascination towards early success stories (rightly or wrongly), provide a powerful advert to other students within compulsory education around the world of the potential experiences that are on offer at US Golf Academies. As a prerequisite for their future progression, such international students are offered additional English language support as part of their academy program; again with a focus of ensuring they are eligible for a college scholarship.

\section{How are US Academies run?}

Most US golf academies follow a similar organizational structure, including Owner, Chief Operating Officer, Board, Director of Golf/Instruction, and then a series of Lead and Support/Assistant Instructors. Most academy owners have been professional tournament 
golfers or coaches themselves and have a track record of business acumen. Notably, however, few have an academic background or experience working in talent development per se. Historically, many of the instructors employed by the owners have been skilled golfers too and are professed experts in their field. However, rather than being US Professional Golfers' Association qualified (the recognized US industry body for golf professionals), they instead become certified instructors through the academies' own in-house processes (e.g., TPI, 2015; David Leadbetter, 2015; Jim McLean, 2015). This process includes the instructors reading material, presenting information, watching lessons, and demonstrating golf skills. A further recent development at Core Golf Academy is the establishment of a Golf Advisory Board. Here, instructors are given the opportunity to attend seminars run by Board members on specific subject matter such as Trackman technology, three-dimensional motion capture, strength and conditioning, and Putting Optics (Core, 2015c). Despite the claims and testimonies provided on the academy websites, however, there is no official independent validation of the coaches' professional practice. No members association exists to regulate and quality assure the academies' delivery as undertaken by the NCAA in College sport. Such a body which could deliver independent quality evaluations of owners, staff, and support workers against recognized national standards could provide the talent tourist with valuable data on which to base their selection.

Academies seem to have invoked their own status and protocols within the US talent pathway which currently sit outside any formal reporting mechanism. Supporting the status in which golf academies are held, Lorin Anderson, president of the Proponent Group which works as an advisor for top golf instructors, points to the exaggerated salaries commanded by their workers. He suggests that comparing salaries for professionals in the golf industry would position academy owners and their teams high above the average annual salary bands $(\$ 500,000)$. For example academy Directors of Golf/Directors of Instruction salaries are 
comparable with Head Coaches of college programs at Major Conference Schools and earn an average of $\$ 125,000$, whilst even academy Instructors receive an average $\$ 40-60,000$, compared with the average PGA salary of $\$ 55,000$ (Anderson, 2015).

\section{US Golf Academies: Truly Expert Environments or just a Well-Publicized Self-}

\section{Fulfilling Prophecy?}

With the potential reward on offer (i.e., college scholarship/Tour card) it is no surprise that those from outside the US wish to gain access to the pathway. As described in the sections above, US golf academies offer an interesting new entry point and unprecedented level of preparation for the events at which talent identification and college scholarship awards are decided upon, and on which our talent tourists' golfing futures may depend. Considering the vast sums of money that these tourists and their sponsors are willing to pay in searching for the "golden ticket" and a place at a US golf academy, it is interesting to explore on what basis their "buying decision" might be made and how the various academies promote their offer to influence this decision in light of the dearth of comparative data available in the public domain.

On initial inspection of academies' websites and promotional materials (e.g., Bishops Gate, 2015b; Core, 2015b; Eagles Dream, 2015; Gary Gilchrist, 2015; Saddle Brook, 2015b), it is clear that all offer outstanding physical facilities, locations which benefit from exceptional natural climates, and position themselves with very similar price points for the premium service they promote. From a human resources perspective, all promote the quality of their instructional teams, accumulated wealth of experience, and track record of working with successful players and teams (Annika, 2015; IMG, 2015e; Jim McLean, 2015; Mike Bender, 2015; Tim Sheredy, 2015). What is not clear, however, is on what basis such claims are made. Against what measures are both the appropriateness of the equipment and the facilities' operation to be assessed? In respect to the instructional teams, we must also ask 
how the quality of the experience was gained, the training selected, and the coaches' actual professional practice evaluated? Without this information being explicitly stated, how are the talent tourists to make the best decision for their future careers?

Literature from many non-golfing domains explores the consumer decision making process when buying a product or service (Hanson, Schiffman, \& Kanuk, 2011; JanssonBoyd, 2010; Solomon, Barnossy, Askegaard, \& Hogg, 2009). Although a detailed discussion of this process is beyond this paper's scope (see Blackwell, Miniard, \& Engel, 2001, for a more complete description of the Consumer Decision Process Model), the personal, psychological, and social factors (Blythe, 2009) that influence this process are highly pertinent. A greater understanding of how these three factors might interact to impact on the talent tourists' academy selection in practice (i.e., perceptions of quality, value for money, brand loyalty/awareness, cost-benefit analysis, efficacy of staff/coaches, track records etc.) seem important at this early stage of exploration and, therefore, warrant further examination.

Beech and Chadwick (2007) separate the influences of these factors as either internal or external inputs to the decision. Personal and social external factors such as demographics, family and reference groups, culture, religion, and situational factors, do bear influence on buying decisions, but it is the internal psychological factors, such as the consumer's perceptions, motivation, learning, attitude, and personality, that have a more direct link and impact. Therefore, it is these components of this particular factor that we are interested in for our talent tourists.

"Perception involves a three-step process of selecting, organizing and interpreting information to produce meaning” (Dibb, Simkin, Pride, \& Ferrell, 2012, p. 159). Accordingly, for our talent tourists, the information on offer when selecting their academy is inextricably linked with the marketing materials, publicity, and details obtained through online interaction, and their recruitment visits to the individual facilities. From the key points 
evident on academy websites and reinforced in their marketing materials, it appears that focus has been directed towards promoting the quality of facilities, coaching team's pedigree, location and suitability of living accommodation, pastoral care systems, academic tutoring and partnered schools, golf instruction, and level of sport science support. Our concern here, once again, references our previous point regarding the lack of benchmarked performance standards against which such claims and marketing promotion could be evaluated and used as a filter by our talent tourists in order to disregard erroneous information and eliminate those academies from their list of potential selections. Of course, an important consideration may also be the talent tourists' sponsors' input into this perception element of the buying process. In particular their own value-for-money perceptions and evaluation of the potential return on their investment. This may be in terms of the academies' supply of golf rounds played, time for practice, quality of lessons, access to the best technology, qualifications of golf staff and academic professors, and all are strategically targeted to resonate with their customers' intended outcome of gaining a prized college scholarship and motivate them to buy into the academy's performance lifestyle. Again, an independent body which provided a fees comparison against outcome data on the percentage of players who progressed into college golf would be invaluable for sponsors to base their judgement of potential return on their investment. As another parallel component, such comparisons could also focus on process data, reporting on the TD systems and methods used against the evidence available in the burgeoning literature in this field.

As we focus specifically on the internal psychological factors that will drive and cement the academy buying process, we must also consider our players' motivations. Elliot and Covington (2001) note that motivation is a set of mechanisms for controlling movement towards goals. As our talent tourists' motives lie in developing their golf performance and securing a prestigious college scholarship, it is no surprise that the academies' track record of 
alumni success is highly promoted through many communication channels. Conversely what may be equally of interest to the talent tourist and their sponsor is what exit data are available about those players who do not progress into college golf. How satisfied were these players with the experience they received and where has their career now taken them? A central repository of post hoc reviews (open rather than solicited a la 'Trip Advisor') could offer a great service to the aspirant tourist!

The next internal psychological factor to be considered is the players' learning. Within the academy buying process context, learning here refers to changes in behavior caused by information and experience, and the ability to process this new information. This directly manifests itself here, with academies offering trial periods in which to expose the potential buyer to their particular brand of support. Examples range from potential talent tourists being offered exemplar golf instructional sessions, rounds on the academy golf course in the company of existing student-athletes who augment and reinforce the available information, and residential stays at academies so they can learn and experience first-hand the lifestyle and pastoral support that is on offer. One may ask though how representative is this experience of a typical day for a talent tourist. Again we highlight the benefit to be gained by establishing an independent body which could provide unprejudiced public reports on each academies' offer.

The final contributors to the academy selection process are the attitudes and personality of the consumer. Here, attitudes are the individual's enduring feelings towards the product or service and belief that enrolling into a specific academy will positively enhance their chances of goal achievement (Ajzen, 1991). Whereas, personality refers to that individual's internal traits and behaviors that make that person unique. Attitudes consist of three components - cognitive, behavioral, and affective elements. The cognitive element concerns knowledge of an object or idea, the behavioral attitude reflects the action tendencies 
exhibited towards the object/idea, whilst the affective element describes the feelings one has towards said object or idea. As noted above, the academies' marketing and promotion clearly focus on these first two elements in order to foster a positive attitude towards their product. For example the Gary Gilchrist Golf Academy website states that "CHAMPIONS ARE MADE NOT BORN. At the Gary Gilchrist Golf Academy, our mission is to provide the best junior golf academy environment that allows junior golfers to reach their true potential. Your road to College Golf starts here" (Gary Gilchrist, 2015). For the talent tourist, however, where is the objective data to counter the marketing messaging?

In addition to the academies' promotions noted above, an environment or culture is often articulated to portray a family atmosphere, a close, welcoming and supportive community in order to connect with the talent tourists' inner desires and self-concepts and evoke positive emotions. Indeed, many academies also target their information and promotion at certain personality types in order to give them the best chance at influencing their attitudes and have a more positive effect on their buying decision. In contrast, other larger academies offer a "blanket approach," offering something for everyone so individuals will inevitably relate to the venue and offer.

So, on first inspection the golf academies seem homogenous in program and facilities. However, a deeper observation reveals that this market is segmented into subdivisions based on size and preferred customer, developing a specific offer to appeal to the targeted personality type but also the personal and social elements of the buying process (Dibb et al., 2012). For example, the Eagle's Dream Academy focusses its attention on Chinese golfers, offering coaching and pastoral practices aligned to the Chinese culture and language (Eagles Dream, 2015). Annika Golf has targeted those golfers who prefer more individualized attention, thus limiting the number of players they will recruit in order to maintain low coach to player ratios (Annika, 2015). Saddle Brook promotes a resort-based experience where 
golfers live, train, and are educated on site with open access to resort level quality training and leisure facilities (Saddle Brook, 2015b). Bishops Gate markets a more exclusive high end experience with their players living and practicing on their very own golf course (Bishops Gate, 2015b). IMG promote the most performance-focused elite level training environment on offer with career-focused athletes from many different sports sharing stateof-the-art facilities (IMG, 2015d), whilst Core promotes the most student welfare based program (Core, 2015). With no current unbiased and impartial compendium of information however, how would our talent tourist ensure that they made the correct personal choice and did not waste valuable time, money, and effort after making an ill-informed decision?

In this section, we have explored US golf academies' operation, curriculum, and promotional activities aimed at influencing the customers' buying decision. We have highlighted significant information gaps by which the talent tourist can make an informed decision. A genuine requirement for creating a range of performance evaluation metrics by which to evaluate the academies' effectiveness has been exposed. In doing so we have identified a real need for the establishment of an impartial and independent body that could oversee the recording and publicizing of the results, and also validate the academies' marketing claims.

\section{Areas for Future Research}

Although the demonstration of current academy practices is interesting for readers who sit outside of the US system, the greater resonance here would be a critical analysis of the observed practice based on the evidence in TDEs, and discussion of how academies may choose to develop their offer in future. In reference to this point, we note how the current talent tourists might base their buying decisions on perceptions of expertise gained from professionally constructed marketing materials, testimonies, and well publicized coaching biographies. We may ask, however, to what extent these perceptions are a valid measure of 
quality? Expertise is inextricably linked to the decision making input of coaches and deliverers (Collins, Collins, \& Grecic, 2015; Grecic \& Collins, 2012; Martindale \& Collins, 2005, 2012; Lyle, 2002, 2010), and knowledge is a key determinant of expert decision making and behavior (Bentham, 2004; Grecic \& Collins, 2013; Nash \& Collins, 2006). Accordingly, it would be interesting to mirror previous research into coach learning and development (Erickson, Côté, \& Fraser-Thomas, 2007; Gilbert, Lichtenwaldt, Gilbert, \& Côté, 2009; Jones, Wallace, \& Potrac, 2003; Mallett, 2010; Nash \& Sproule, 2009; Schempp, Templeton, \& Clark, 1998; Wright, Trudel, \& Culver, 2007) and interview academy coaches to gain their interpretations on the operation, ethos, success, and knowledge base which underpins their coaching philosophy and their academies' "sell” (Bennie \& O'Connor, 2010; Grecic \& Palmer, 2013; Grecic, MacNamara, \& Collins, 2013; Nash, Sproule, \& Horton, 2008). Indeed, all the academies we researched, professed a desire to create a positive, supporting environment for their players to train in, but how close is this environment a true holistic and player-centered TDE? (Henriksen, Stambulova, \& Roessler, 2010; Kidman, 2005; Martindale et al., 2007). After all, it is an ultimate goal of these academies to develop players that are equipped to succeed on the professional tour. To provide a best possible service to golfers seeking a career in professional golf, it is therefore necessary to determine whether these academy coaches' professional practice is actually modelled on holistic values and evidence-based research which promotes long-term developmental aims and methods, wide ranging coherent messages of support, and individualized and on-going development. If not, then we need to ask "why not?" and support the academies on their own developmental and learning journey. Alternatively, it may be the case that US academies are simply operating an income-led business model which relies on sophisticated sales and marketing and preys on young golfers' and their parents internal motives? They may be very successful as a commercial business but surely this needs to be explicitly explained to our talent tourists 
when they are considering their options? Indeed, a crucial aspect of the talent pathway for most, unfortunately, is knowing when to seek alternative opportunities.

Another pertinent and interesting line of investigation would be to explore how the academy coaches gain their positions, develop their knowledge and self-professed expertise to perform their TD practices. Are they actually as "expert" in TD as the talent tourists are led to believe? Indeed, the development of expertise has long been an area of research interest, and has been studied within many domains from a variety of approaches (see Allard \& Starkes, 1993; Berliner, 1994; Ericsson, Krampe, \& Tesch-Römer, 1993; Ericsson 1996; Starkes \& Ericsson, 2003). Notably, findings have revealed similar trends/themes regarding the nature of such expertise once it has finally been acquired, which Nash and Collins (2006) summarized as being:

domain specific and developed over a prolonged period of time; experts recognize patterns faster than novices; expert knowledge is structured to allow easier recall; experts sort problems into categories according to features of their solutions; experts initially are slower to solve problems than non-experts but are faster overall; experts are more flexible and are more able to adapt to situations; experts develop routines to allow processing capacity to be focused on on-going environments; and experts take deeper meanings from cues than novices. (p. 466)

It would therefore be of great interest to apply such standards to the academy coaches' professional practice in an attempt to validate their claims.

Following this line of reasoning, it would also be extremely valuable to gain different stakeholders' perceptions of whether the academies are, in fact, developing expertise in their golfers. We suggest that worthy lines of investigation could include the following areas: how young golfers are equipped with the ability to successfully refine their golfing skills (Carson \& Collins, 2011) considering that all golfers seeking scholarships would already be in 
possession of well-established golf swing techniques (Carson \& Collins, 2016); the psychological characteristics to develop excellence in their game (PCDEs; Gould, Dieffenbach, \& Moffatt, 2002; MacNamara, 2011); whether the academy staff sufficiently understand the skill development process to continually develop this expertise (Carson \& Collins, 2011; Carson, Collins, \& MacNamara, 2013; Toner \& Moran, 2015); and if so, on what basis are their decisions about this process being made (PJDM; Martindale \& Collins, 2005, 2012). Indeed, we need to delve deeper to ascertain just how effective and impactful the academies are, whether they are actually worth the money paid by the talent tourists, and how adept they are in supporting developments in skill and the life stage transitions that will face these future elite athletes (Wylleman, Alframann, \& Lavalle, 2004; Collins \& MacNamara, 2012)? Interviews with college head coaches, AJGA tournament organizers, parents, and current academy players would offer fascinating observations, opinions, and further insights into this route of the US golfing pathway and provide a developmental framework for academies to constantly modify and improve their product (Collins \& Cruickshank, 2012; Cruickshank \& Collins, 2012, 2013; Fletcher \& Arnold, 2011; Pankhurst, Collins, \& MacNamara, 2013; Sotiriadou \& Shilbury, 2013).

\section{Summary}

This paper has started an exploration into the growing phenomenon of US academies. It has revealed a new talent pathway route for non-US resident golfers into elite-level golf. The structure and operation of US golf academies within this pathway has been described, whilst the reasons behind how and why these might have become a popular option for twenty first century talent tourists have been displayed. Finally we have discussed the question of how justifiable the academies' claims are of being an expert nurturer of talent and how we could delve deeper into this area. In doing so we have highlighted the need to establish robust and valid performance measures and evaluative processes in order to provide 
invaluable information for our future talent tourists. We look forwards to comment, debate and further data to drive this exploration. 


\section{References}

Abraham, A., Collins, D., \& Martindale, R. (2006). The coaching schematic: Validation through expert coach consensus. Journal of Sport Sciences, 24, 549-564.

Abraham, A., \& Collins, D. (2011a).Taking the next step: Ways forward for coaching science. Quest, 63, 366-384.

Abraham, A., \& Collins, D. (2011b). Effective skill development-how should athletes' skills be developed. In D. Collins, A. Button, \& H. Richards, (Eds.), Performance psychology: a practitioner's guide. (pp. 207-230). Oxford: Elsevier.

AJGA (2015). American Junior Golf Association, Coaches Selections at Competitions 2015 Retreived from https://www.ajga.org/Parents/BrooksTop10.asp.

Ajzen, I. (1991). The theory of planned behavior. Organizational Behavior and Human Decision Processes, 50, 179-211. doi:10.1016/0749-5978(91)90020-T

Alfremow, J. (2015). The champion's mind: How great athletes think, train and thrive. New York, Rodale

Allard, F., \& Starkes, J. (1993). Cognitive issues in motor expertise. Amsterdam: NorthHolland.

Anderson, L. (2015). Personal communication - interview conducted on June $5^{\text {th }} 2015$. Annika (2015) Elite Training Program 2015. Retrieved from http://theannikaacademy.com/about-elite program/program

Balyi, I, (2002). Long-term Athlete Development, the System and Solutions. FHS, 14, 6-9.

Bailey, R., Collins, D., Ford, P., Macnamara, A. Toms, M. and Pearce, G. (2009) Participant Development in Sport: an academic review. Leeds: sports coach UK.

Beech, J., \& Chadwick, S. (2007). The marketing of sport. Prentice-Hall: Harrow. 
Bennie, A., \& O’Connor, D. (2010). Coaching philosophies: Perceptions from professional cricket, rugby league and rugby union players and coaches in Australia. International Journal of Sports Science and Coaching, 5, 309-321.

Bentham, R.H., (2004). Expertise in sport instruction: Pedagogical content knowledge among expert golf instructors. Research Quarterly for Exercise and Sport, 75(1), Supp, A59

Berkowitz, S (2015). Landmark decision on College scholarship awards 2015. Retrieved from http://www.usatoday.com/story/sports/college/2015/01/17/ncaa-convention-costof-attendance-student-athletes-scholarships/21921073/

BBC. (2014). BBC documentary Charley Hull: Teenage Tigress 2014. Retrieved from http://www.bbc.co.uk/sport/0/golf/27049698

Berliner, D.C. (1994). Expertise: The wonder of exemplary performances. In J. Mangieri \& C. Block, (Eds.), Creating powerful thinking in teachers and students: Diverse perspectives, (pp. 161-186), Fort Worth, Texas: Harcourt Brace College

Bishops Gate (2015a). Bishops Gate Program 2015. Retrieved from https://www.bgga.com/programs.html

Bishops Gate (2015b). Bishops Gate Experience 2015. Retrieved from https://www.bgga.com/experience.html .

Blackwell, R., Miniard, P. \& Engel. J. (2001). Consumer behaviour. Harcourt: Orlando Blythe, J. (2009). Principles and practice of marketing ( $2^{\text {nd }}$ ed.). South-Western publishing: China

Bowes, I., \& Jones, R. (2006). Working at the edge of chaos: Understanding head coaching as a complex interpersonal system. The Sport Psychologist, 20, 235-245.

Carson, H.J., \& Collins, D. (2011). Refining and regaining skills in fixation/diversification stage performers: The Five-A Model. International Review of Sport and Exercise Psychology, 4, 146-167. doi: 10.1080/1750984X.2011.613682 
Carson, H.J., \& Collins, D. (2016). The fourth dimension: A motoric perspective on the anxiety-performance relationship. International Review of Sport and Exercise Psychology, 9, 1-21. doi: 10.1080/1750984X.2015.1072231

Carson, H.J., Collins, D., \& MacNamara, Á. (2013). Systems for technical refinement in experienced performers: The case from expert-level golf. International Journal of Golf Science, 2, 65-85

College Golf Combines (2015). Portfolios 2015. Retrieved from http://www.collegegolfcombines.com/2015-college-golf-coaches-conventioncombine.cfm

Collins, D., Bailey, R., Ford, P. A., MacNamara, Á., Toms, M., \& Pearce, G. (2012). Three Worlds: new directions in participant development in sport and physical activity. Sport, Education \& Society, 17, 225-243.

Collins, D., Burke, V., Martindale, A., \& Cruickshank. A. (2015).The illusion of competency versus the desirability of expertise: Seeking a common standard for support professions in sport. Sports Medicine, 45(1),1-7. doi: 10.1007/s40279-014-0251-1

Collins, L., Collins, D., \& Grecic, D. (2015). The epistemological chain in high-level adventure sports coaches. Journal of Adventure Education \& Outdoor Learning, 15, 224-238.

Collins, D., \& Cruickshank, A. (2012). 'Multi-directional management': exploring the challenges of performance in the World Class Programme environment. Reflective Practice, 13(3), 455- 469.

Collins, D., \& MacNamara, Á. (2012). The rocky road to the top. Sports medicine, 42, 907914.

Core (2015a). Programs 2015. Retrieved from http://www.coregolfacademy.com/programs.html 
Core (2015b). The Course 2015. Retrieved from

http://www.coregolfacademy.com/life.html\#course

Core (2015c). Uniqueness 2015. Retrieved from http://www.coregolfacademy.com/coreadvantage.html\#uniqueness

Côté, J., \& Gilbert, W. (2009). An integrative definition of coaching effectiveness and expertise. International Journal of Sports Science and Coaching, 4, 307-232.

Coyne, D. (2009). The Talent Code: Unlocking the secret of skill in maths, art, music, sport, and just about everything else. London, Random House

Cruickshank, A., \& Collins, D. (2012a). Culture change in elite sport performance teams: Examining and advancing effectiveness in the new era. Journal of Applied Sport Psychology, 24, 338- 355. doi:10.1080/10413200.2011.650819

Cruickshank, A., \& Collins, D. (2013). Culture change in elite sport performance teams: An important and unique construct. Sport \& Exercise Psychology Review, 9(2), 6-21.

Cushion, C.J., Armour, K.M., \& Jones, R. (2003). Coach education and continuing professional development: experience and learning to coach. Quest, 55, 215-230.

David Leadbetter (2015). David Leadbetter Instructor Training Program 2015. Retrieved from http://davidleadbetter.com/how-to-get-certified/

Dibb. S., Simkin. L., Pride. W., \& Ferrell, O. (2012). Marketing concepts and strategies (6 $6^{\text {th }}$ edn.). Cengage Learning: China

Eagles Dream (2015). Introducing the Home of Future Champions - Eagles Dream Golf Academy 2015. Retrieved from http://www.eaglesdream.com/

Ellliot, A. \& Covington, M. (2001). Approach and avoidance motivation. Educational Psychology Review 13, 2. 
England Golf. (2010). England Golf Long Term Athlete Development Resource Pack. England Golf

English Golf Union. (2011). The road to world class or from County Golf to the World Stage. EGU.

England Golf Partnership. (2013). English Golf Partnership Whole Sport Plan 2013-17 Summary Document. England Golf

England Golf. (2014). Raising Our Game Together: The Strategic Framework for Golf 20142017. England Golf

Epstein, D. (2014). The Sports Gene: Inside the science of extraordinary athletic performance. London, Random House

Ericsson, K. A. (1996). The road to excellence: The acquisition of expert performance in the arts and sciences, sports, and games. Mahwah, N.J.: Lawrence Erlbaum Associates.

Erickson, K., Côté, J., \& Fraser-Thomas, J. (2007). Sport experiences, milestones and educational activities associated with high performance coaches' development. The Sport Psychologist, 21, 302-315.

Ericsson, K., Krampe, R., \& Tesch-Römer, C. (1993). The role of deliberate practice in the acquisition of expert performance. Psychological Review, 100, 363-406.

Fletcher, D., \& Arnold, R. (2011). A qualitative study of performance leadership and management in elite sport. Journal of Applied Sport Psychology, 23, 223-242. doi:10.1080/10413200.2011.559184

Gary Gilchrist (2015). Full time junior program 2015. Retrieved from http://ggga.com/programs/full-time-junior/

Gilbert, W.D., Lichtenwaldt, L., Gilbert, J., Zelezny, L., \& Côté, J. (2009). Development profiles of successful high school coaches. International Journal of Sports Science and Coaching, 4, 415-431. 
Gilbert, W., \& Trudel, P. (2012). The role of deliberate practice in becoming an expert coach: Part 1 - Defining coaching expertise. Olympic Coach Magazine, 23(3), 19-24

Gilbert, W., \& Trudel, P. (2013a). The role of deliberate practice in becoming an expert coach: Part 2 - Reflection. Olympic Coach Magazine, 24(1), 35-44.

Gilbert, W., \& Trudel, P. (2013b). The role of deliberate practice in becoming an expert coach: Part 3 -Creating optimal settings. Olympic Coach Magazine, 24(2), 15-28.

Gladwell, M. (2009). Outliers: The story of success. London, Penguin

Golfweek (2015a). Boys Junior Rankings 2015. Retrieved from http://rankings.golfweek.com/rankings/default.asp?T=boys

Golfweek (2015b). NCAA Player Listings 2015. Retrieved from http://golfweek.com/lists/ment/ default.asp?T=men

Gray, D. (2015). How coaches talent ID importance of competitions 2015. Retrieved from http://danielrgray.com/collegiate-division-1-golf-coach-interviews/

Grecic. D., \& Collins, D. (2012). A qualitative investigation of elite golf coaches' knowledge and the epistemological chain. Journal of Qualitative Research in Sport, 6(1). 49-71.

Grecic, D., \& Collins, D. (2013). The Epistemological Chain: Practical applications in sports. Quest, 65, 151-168. doi.10.1080/00336297.2013.773525

Grecic, D., MacNamara, A., \& Collins, D. (2013). The epistemological chain in action: coaching in high level golf. Journal of Qualitative Research in Sports Studies, 7(1), $103-126$.

Grecic, D. and Palmer, C. (2013) Tales from the tee: narrative accounts of being coached in golf. Journal of Qualitative Research in Sports Studies, 7, 1, 127-152.

Green, M., \& Houlihan, B. (2008). Comparative elite sport development: Systems, structures and public policy. Butterworth-Heinemann: London. 
Greg Norman (2015). Greg Norman Champions Golf Academy 2015. Retrieved from http://www.gncga.com/full-time-overview

Gould, D., Dieffenbach, K., \& Moffatt, A. (2002). Psychological characteristics and their development in Olympic champions. Journal of Applied Sport Psychology, 14, 172 204.

Hanson. H., Schiffman. L., \& Kanuk, L. (2011). Consumer behaviour. Prentice Hall: London. Henriksen,K., Stambulova, N., Roessler, K.K. (2010). Holistic approach to athletic talent development environments: A successful sailing milieu. Psychology of Sport \& Exercise, 11, 212-222. doi:10.1016/j.psychsport.2009.10.005

Hodges, N., \& Baker, J. (2011). Expertise: the goal of performance development. In D. Collins, A. Button, \&H. Richards, (Eds.), Performance psychology: A practitioner's guide. (pp. 31-46), London.

Horton, S., Deakin, J., \& Hunt, P. (2008). Expert coaches in action. In. Farrow, D. (ed.), Developing sport expertise: Researchers and coaches put theory into practice, (pp.75-88). London, Routledge,

IJGA (2015). International Junior Golf Academy Our Program 2015. Retrieved from http://ijga.com/full-timeprogram/?keyword=international $\% 20$ junior $\% 20$ golf $\% 20$ academy \&matchtype=b $\&$ gcli d=CNKgo5TzwsgCFUYXHwody9sBig

IMG (2015a). IMG Golf Academy Notable / Trainees 2015. Retrieved from https://www.imgacademy.com/sports/golf/notable-alumni

IMG (2015b). International Management Group, Where it all began 2015. Retrieved from https://www.imgacademy.com/our-legacy

IMG (2015c). IMG Student athlete program 2015. Retrieved from http://www.imgacademy.com/sports/golf/prep-school-program 
IMG (2015d). IMG Academy 2015. Retrieved from http://img.com/services/imgacademy.aspx

IMG (2015e). IMG Academy Coaches 2015. Retrieved from https://www.imgacademy.com/sports/golf/coaches

Janson-Boyd. C. (2010). Consumer psychology. Open University Press: Oxford Jim McLean (2015). Jim McLean Junior Golf Academy 2015. Retrieved from http://jimmclean.com/locations/texas-golf-center/junior-academy

Jones, R., Wallace, M., \& Potrac, P. (2003). Constructing expert knowledge: A case study of a top level professional soccer coach. Sport, Education, and Society, 8,213-229.

JPGA (2015). Junior Players Golf Academy - Full Time Program 2015. Retrieved from http://www.jrpga.com/junior-golf-academy-full-time.php

Junior Golf Scoreboard (2015). How do College coaches discover talent? Planning your competitive season to gain exposure among college coaches 2015. http://www.juniorgolfscoreboard.com/ss_4_archive.asp?passsskID=15

Junior Golf Scoreboard (2015b). Junior Golf Scoreboard rankings 2015. Retrieved from https://www.juniorgolfscoreboard.com/rankings_display.asp

Kidman, L. (2005). Athlete-centred coaching. Innovative Print Communication Ltd: Christchurch.

Lyle, J. (2002). Sports coaching concepts: A framework for coaches' behaviour. Routledge: London

Lyle, J. (2010). Coaches' decision making: A naturalistic decision making analysis. In J. Lyle \& C.J. Cushion (Eds.), Sport coaching: Professionalisation and practice (pp. 27-41). London: Churchill Livingstone. 
MacNamara, Á. (2011). Psychological characteristics of developing excellence. In D. Collins, A. Button, \& H. Richards, (Eds.), Performance psychology: A practitioner's guide. (pp. 47-64). London: Churchill Livingstone.

Mallett, C. (2010). Becoming a high-performance coach: pathways and communities. In J. Lyle, \& C. Cushion, (Eds), Sports coaching professionalisation and practice, (pp.119-134). London: Churchill Livingstone.

Martindale, A., \& Collins, D. (2005). Professional judgment and decision making: The role of intention for impact. Sport Psychologist, 19,303-317.

Martindale, R., \& Collins, D. (2012).A Profession Judgement and Decision Making case study: Reflection-in-action research. The Sport Psychologist, 28, 500-518.

Martindale, R. J., Collins, D., \& Abraham, A. (2007). Effective Talent Development: The Elite Coach Perspective in UK Sport. Journal of Applied Sport Psychology, 19, 187206.

Martindale, R., \& Mortimer, P. (2011). Talent development environments: Key considerations for effective practice. In D. Collins, A. Button, \& H. Richards, (Eds.), Performance psychology: A practitioner's guide. (pp. 65-84). London: Churchill Livingstone.

McClusky, M. (2015). Faster, Higher, Stronger: How sports science is creating a new generation of superathletes--and what we can learn from them. New York, Penguin Publishing House

Mike Bender (2015). Mike Bender Elite Golf Academy 2015. Retrieved from http://www.mikebender.com/elite-golf-academy.html

Missing Links (2015). Missing Links Junior Golf Academy Lessons at Lakewood Ranch, Florida 2015. Retrieved from http://www.missinglinkga.net/Student_Focused_Golf_Lessons_Lakewood_Ranch_FL .html 
Nash, C., \& Collins, D. (2006). Tacit knowledge in expert coaching: Science or Art? Quest, $58,464-476$

Nash, C., Martindale, R., Collins, D., \& Martindale, A. (2012). Parametising expertise in coaching: Past, present and future. Journal of Sports Sciences, 30, 985-994.

Nash, C., \& Sproule, J. (2009).Career development of expert coaches. International Journal of Sports Science and Coaching, 4, 121-138.

Nash, C., Sproule, J., \& Horton, P. (2008). Sport coaches' perceived role frames and philosophies. International Journal of Sports Science \& Coaching, 3, 538-554.

NCAA (2015a). International Student Athletes 2015. Retrieved from http://www.ncaa.org/student-athletes/future/international-student-athletes

NCAA (2015b). The value of college sports 2015. Retrieved from http://www.ncaa.org/student-athletes/value-college-sports

NCAA (2015c). NCAA Scholarships 2015. Retrieved from http://www.ncaa.org/studentathletes/future/scholarships

Pankhurst, A., Collins, D., \& MacNamara, Á. (2013). Talent development: linking the stakeholders to the process. Journal of sports sciences, 31, 370-380.

PGATour (2015).Tour Player Information 2015. Retrieved from http://www.pgatour.com/players.html

Saddle Brook (2015a). Saddle Brook Golf Academy 2015. Retrieved from http://saddlebrookgolfacademy.com/

Saddle Brook (2015b). Welcome to our Tampa, Florida Resort 2015. Retrieved from http://saddlebrookgolfacademy.com/index.html

Schempp, P.G., McCullick, B., \& Mason, I.S. (2006). The development of expert coaching. In R.L. Jones (Ed.), The sports coach as educator: Re-conceptualizing sports coaching (pp. 145-161). London: Routledge 
Schempp, P., \& McCullick, B. (2010). Coaches' expertise. In J. Lyle \& C. J. Cushion (Eds.), Sport coaching: professionalisation and practice (pp. 221-323). London: Churchill Livingstone.

Schempp, P.G., Templeton, C.L., \& Clark, B. (1998). The knowledge acquisition of expert golf instructors. In M. Farrally \& A. J Cochran (Eds.), Science and golf III: Proceedings of the world scientific congress on golf, (pp. 295-301), Leeds: Human Kinetics.

Scholarship Statistics (2015). College Golf and Scholarship Opportunities 2015. Retrieved from http://www.scholarshipstats.com/golf.htm

Smolianov, P. (2015). Sport development in the US: High performance and mass participation. Routledge: New York.

Solomon, M., Barnossy. G., Askgaard, S., \& Hogg, M. (2009). Consumer behaviour. Prentice Hall: London.

Sotiriadou, K., \& Shilbury, D. (2013). Sport development in high performance sport. In P. Sotiriadou \& V. De Bosscher (Eds.), Managing high performance Sport, (pp. 139158), London: Routledge.

Starkes, J. L., \& Ericsson, K. A. (Eds.)(2003). Expert performance in sports: Advances in research on sport expertise. Leeds, Human Kinetics

Syed, M. (2011). Bounce: The myth of talent and the power of practice. London, HarperCollins

Tim Sheredy (2015). Tim Sheredy Golf Institute - Peridoization 2015. Retrieved from http://tsgigolf.com/training-junior-golf-philosophy/

TPI (2015). Titleist Performance Institute, TPI junior instructor accreditation 2015. Retrieved from http://www.mytpi.com/certification/about 
Toner, J., \& Moran, A. (2015). Enhancing performance proficiency at the expert level: Considering the role of 'somaesthetic awareness'. Psychology of Sport and Exercise, $16(1), 110-117$.

Wright, T., Trudel, P., \& Culver, D. (2007). Learning how to coach: the different learning situations reported by youth ice hockey coaches. Physical Education and Sport Pedagogy, 12(2), 127-144.

Wylleman, P., Alfermann, D., \& Lavallee, D. (2004). Career transitions in sport: European perspectives. Psychology of Sport and Exercise, 5, 7-20. 